\title{
Methods of bipolar microcircuits learning experiment
}

\author{
S.V. Tyulevin ${ }^{1}$, M.N. Piganov ${ }^{2}$, E.S. Erantseva ${ }^{2}$ \\ ${ }^{1}$ JSC Progress Rocket and Space Centre “Progress”, Zemets St., 18, 443009, Samara, Russia \\ ${ }^{2}$ Samara National Research University, 34 Moskovskoe Shosse, 443086, Samara, Russia
}

\begin{abstract}
The analysis of learning experiment methods of semiconductor microcircuits for individual prediction of their quality is carried out. A choice of the informative parameters and means of their control is made. The schemes of insertion the microcircuits in the course of investigation tests and modes of their control are justified. The analysis of microcircuits constructive and technological options is carried out. The program of investigation tests is developed. Results of learning experiment for 522 series microcircuits are given. The analysis of experimental data is carried out. It is recommended to use results of learning experiment for creation the mathematical prediction models of microcircuits quality.
\end{abstract}

Keywords: learning experiment; bipolar microcircuit; method; investigation tests control; prediction model

\section{Introduction}

The industry way out from crisis in the case of open market economy is almost impossible without solution the problem of improvement the quality and competitiveness of products. The problem of improvement the quality is particularly acute, first of all, before the knowledge-intensive branches of engineering to which also the microelectronics belongs. The main products of microelectronics is integrated microcircuits (IMS). It is taking into account that quality of IMS is defined by their construction, the initial materials, complexity and stability of technological processes. At the same time the main link is the manufacturing technology [1].

One of the conceptual principles of microcircuit quality management can become principles of open quality management. At the same time it is expedient to select the following contours of formation the quality: quality establishment; quality support; quality maintenance; quality prediction; guaranteeing quality; quality improvement [2].

Thus, one of the main stages in formation the microcircuits quality is prediction of their quality indices. For IMS, using in the responsible equipment, the most effective is the individual prediction $[3,4]$. The most important stage of the individual prediction (IP) is the learning experiment.

The learning experiment is a test in the given mode of a certain quantity of the researched products during the required time, usually equal time of the subsequent prediction of $t_{p r}$, and determination the actual state of each specimen of selection to the time of the test end. The purpose of learning experiment consists in receiving the necessary array of initial data, i.e. such array which is required for the subsequent training. The maintenance of initial data array is defined by a type of IP. For example, values of the informative $x_{i}$ parameters (signs) and the predicted $y_{0}$ parameter for all specimen in the initial timepoint, values of the predicted parameter in finite timepoint of $y_{k}$, i.e. in case of $t=t_{p r}$, the intermediate values of the predicted parameter. Sometimes it is required to know the intermediate and finite values of the informative parameters.

Basis of a learning experiment are investigation tests. They allow to reveal, except obtaining the above-mentioned information, processes and schemes of elements degradation, to set types and mechanisms of failures, types of defects, load ranges which accelerate failures. It allows to set up a level of signs informtiveness, criteria of rejection and classification for each constructive and technological option (CTO), to select the most informative parameters, and also to define the modes of technological tests, to optimize the researched CTO, to improve the methods of carrying out the investigation tests, learning experiment and rejection [5].

The most difficult question is determination the types and modes of test influences. They depend on a risk degree or a measure of damage caused in the case of equipment operation. The great problems arise in case of choice the informative parameters, methods and control means.

Imperfection of a stage of learning experiment carries to lowering the accuracy of prediction model, increase in the conditional risks of the supplier and a customer. The work purpose - is a choice of informative parameters and schemes of insertion the 522 series microcircuit when carrying out a learning experiment.

\section{The analysis of learning experiment methods}

The common method of learning experiment in the case of individual prediction the quality indices of space radioelectronic means (REM) is given in [6]. It includes seven main stages:

1. Analysis of constructive and technological features of electric radio products (ERP) and REM.

2. Development or choice the schemes of insertion for control their working capacity and measurement the key parameters.

3. Choice of methods and control means and informative parameters.

4. Determine the selection volume.

5. Development the program of investigation tests.

6. Carrying out investigation tests and experiments.

7. Analysis the test and experiments results.

This method was approved on 286 series microcircuit and showed good results.

Authors [5] within this common approach offered the particular method of carrying out the learning experiment for CMOS type microcircuits. This method provides control of mismatch pulse duration.

For control the informative parameters the installation, containing a dialup field, 2 square waveform oscillator, adapters, comparator, averaging circuit, indication device is offered. As the informative parameter for IMS rejection the propagation delay 
time of a signal in case of turning power on and off is used. At the same time on testing microcircuit they give supply voltage near-critical.

In a number of works the types of test influences when carrying out the diagnostic predicting check are specified.

Many works are devoted to choice and analysis of informative parameters. So, in [7] for prediction of chips quality it is offered to use the level of internal stresses. It is shown that the level of internal stresses depends on the operation modes of diffusion, epitaxy, oxidation, etc. In [8] it was used the distributions of thermal and physical parameters of high-power transistors. Authors in [9] as the informative parameters of semiconductor products on a plate use volt-ampere characteristics (VAC), volt-farad characteristic (VFC) or ampere-noise characteristic (ANC). At the same time they estimate charge stability in case of corona discharge influence. Information of semiconductor devices quality is performed also by m-parameter, which characterizes VAC not ideality level. It was used in case of prediction the transistors durability by image identification methods [10]. High informtiveness in case of electrophysical diagnosing of CMOS types microcircuits was shown by critical power voltage [11]. For quality control of digital integrated microcircuits assembly it is expedient to use matrix parameters of thermal communication [12]. Authors [13] for quality control of light-emitting diodes and semiconductor lasers suggest to use thermomechanical stresses. They arise both as a result of change the ambient temperature, and as a result of sharply heterogeneous self-heating of the instrumental structures by dissipation power. In [14] it is set that it is possible to estimate the semiconductor devices reliability by the value of mechanical stresses. They arise because of distinction the thermal extension coefficients of the applied materials. At the same time the concentration of minority carriers of a charge, their mobility and lifetime change, the energy levels displace.

To predict the drift of semiconductor devices parameters in time and their durability alloys m-parameter [15].

For a kind of transistors with a small area of emitter after passage the several pulses of current through direct switches emitter junction in the active standard mode there can be considerable leakage currents of emitter junction, increasing basis current in the micromode and reducing the current amplification factor [16]. On value of a leakage current they estimate quality of a product.

Authors [17] suggest to estimate CMOS type microcircuits quality on value of critical power voltage after influence of electric discharge. Rather informative parameter for many types of semiconductor devices quality is low-quality noise.

\section{The analysis of the researched microcircuits CTV}

For research and analysis of control and testing processes of 522 series microcircuits were selected, as at them failures were watched earlier. Key parameters of $522 \mathrm{KH}$ microcircuits are specified below.

Residual voltage at the output of microcircuit, with $\mathrm{I}=\mathrm{I}_{\text {out.max., }}$,

$\mathrm{U}_{\text {res., }} \mathrm{V}$

Failure voltage, $\mathrm{U}_{\text {fail., }} \mathrm{V}$ :

Input \#4 - \#3

Input \#4 - \#2

0,35

0,7

47

Disruptive voltage across power circuits, $\mathrm{U}_{\text {disr }}, \mathrm{V}$

Current consumption in closed condition, $\mathrm{I}_{\text {cons.., }} \mu \mathrm{A}$

Coefficient of return, $\mathrm{K}$

$$
\text { no more }
$$

no less

Supply voltage, $\mathrm{U}_{\mathrm{sv}}, \mathrm{V}$

Output amperage $\left(-60 \ldots+85^{0} \mathrm{C}\right), \mathrm{I}_{\text {out }}, \mathrm{mA}$

The power dissipated in the chip package

$\left(-60^{\circ} \mathrm{C} \ldots+25^{\circ} \mathrm{C}\right), \mathrm{P}_{\text {diss. }}, \mathrm{W}$

Active load value, $\mathrm{P}_{\text {load }}, \Omega$, no less

Inductive load value, $\mathrm{L}_{\text {load }}$, $\mathrm{H}$, no more

0,22

Maximum permissible voltage between terminals, $U_{\max }, \mathrm{V}$

1-3, 14-3, 1-2, 14-2,

4-3, 2-3, 2-1, 2-14

Residual voltage at the output of microcircuit

in the absence of loading, $\mathrm{V}$

Maximum switching time, $\mu \mathrm{s}$

Maximum operating frequency, $\mathrm{Hz}$

Resistance of circuit in the open state (with $\mathrm{I}=\mathrm{I}_{\text {out. } \max }$ ), $\Omega$

Emission amplitude at the top of the output pulse, U, V

3

The researches carried out by the authors showed the expediency of using the residual voltage of the microcircuits as an informative parameter.

\section{The switching on schemes}

For measuring the electrical parameters the switching on schemes, adducing on fig. 1-5, were offered. At measuring the $\mathrm{U}_{\mathrm{srb}}$ and $\mathrm{K}$ parameters the supply voltage is applied to the chip before submission the signals on the microcircuit inputs, switchoff is made upside-down. In remaining cases the signals first of all are applied on the microcircuit inputs, then - supply voltages as their increase are given, switch-off is made upside-down. 
In the case of measuring the electrical parameters and testing the microcircuits it is allowed the simultaneous submission and switch-off supply voltage and signals on inputs and outputs of microcircuits. An error of setting up the test voltage and supply voltages must not exceed $\pm 2 \%$, test currents $- \pm 4 \%$.

Measuring instruments of a direct current and voltage shall have an accuracy class not worse than 1,0. The accuracy class of voltmeters - indicators of voltage level meters isn't regulated. Checking the values of supply voltage is made by the accuracy class voltmeter not worse 1,0 with input resistance at least $10 \mathrm{k} \Omega / \mathrm{V}$.

Metrological aspects of control are given in [18].

Measuring the residual voltage on the output of integrated microcircuit in the case of $\mathrm{I}=\mathrm{I}_{\text {out.max. }}$ is carried out according to the measurements scheme provided on fig. 1.

Value of the output current of $\mathrm{I}=\mathrm{I}_{\text {out.max. }}$ is set $\left(\mathrm{R}_{3}\right.$ resistor) by active component of equivalent loading and power supply $E_{2}$. In case of connection the output $I_{3}$ over the $R_{2}$ resistor with $E_{2}$ minus, the mirocircuit connects loading to the power supply, through $R_{3}$ run current of $I=I_{\text {out.max., }}$ causing existence of residual voltage $U_{\text {res }}$.

Value of $U_{\text {res }}$ is controlled by the PV voltmeter.

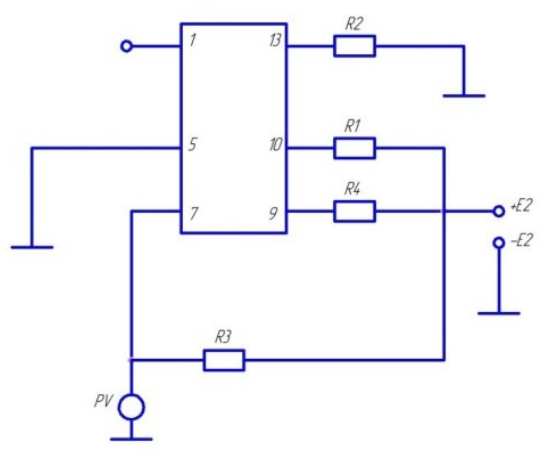

Fig. 1. Scheme of measurement the residual voltage.

Measurement of the operating voltage $U_{\text {oper }}$ is carried out according to the scheme shown on fig. 2.

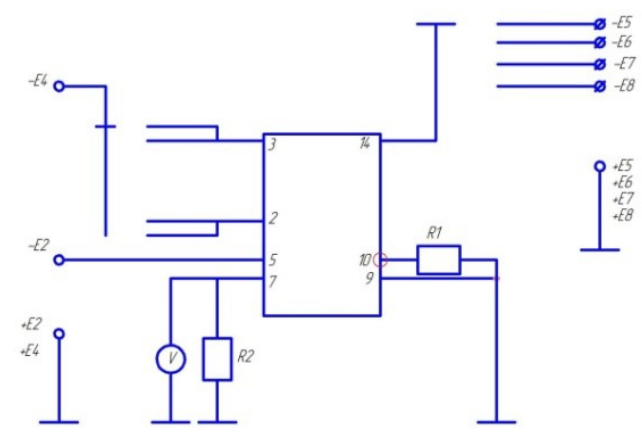

Fig. 2. Scheme of measurement the operating voltage.

The operation voltage $U_{\text {oper }}$ is called the minimum voltage, applied to the microcircuit input, that calls the connection of load to the power supply.

The microcircuit has two control inputs: input \# 4 - \# 3 and input \# 4 - \# 2.

Value of voltage $\mathrm{U}_{\text {oper }}$ is set discretely by power supplies $\mathrm{E} 4$ - E8. The presence or absence of the loading connection to the power supply registers the PV voltmeter - indicator of voltage level.

Measurement of the failure voltage $U_{\text {fail }}$ are carried out according to the same scheme of measurement (fig. 2).

The failure voltage $\mathrm{U}_{\text {fail }}$ is called the maximum voltage applies to the microcircuit input which doesn't yet cause connection of loading to the power supply.

Value of voltage $\mathrm{U}_{\text {fail }}$ is set discretely by power supplies $\mathrm{E} 4-\mathrm{E} 8$.

In the voltage range between $U_{\text {oper }}$ and $U_{\text {fail }}$ for the same control input, the microcircuit can either connect the load to the power supply or not connect it.

Measuring the consuming current in the closed status $\mathrm{I}_{\text {cons }}$. of the microcircuit and disruptive voltage in the supply circuits is carried out simultaneously according to the measurement scheme shown in Fig. 3.

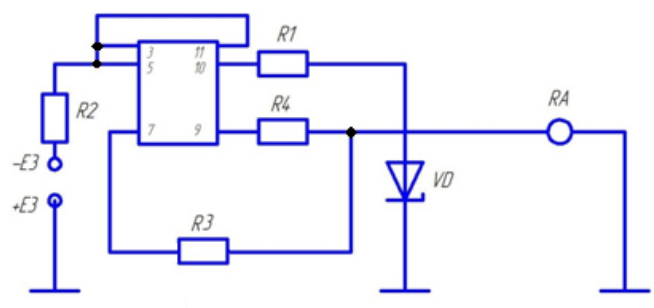

Fig. 3. Scheme of measurement the consumption current and disruptive voltage. 
Consumption current in the close state is the current flowing through the circuits of the microcircuit power supply, when the voltage is not supplied to the load by the microcircuit.

The disruptive voltage through the supply circuits is the maximum voltage applied to the microchip over the power circuits, which does not yet cause the load to be connected to the power supply without input signal.

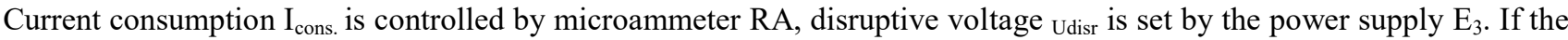
microcircuit does not comply with technical requirements for the disruptive voltage $\mathrm{U}_{\text {diss, }}$, the current consumption $\mathrm{I}_{\text {cons. }}$. will be more than values specified in this requirements.

Control of the operation at maximum operating frequency of $100 \mathrm{~Hz}$ is carried out according to the control scheme shown in Fig. 4.

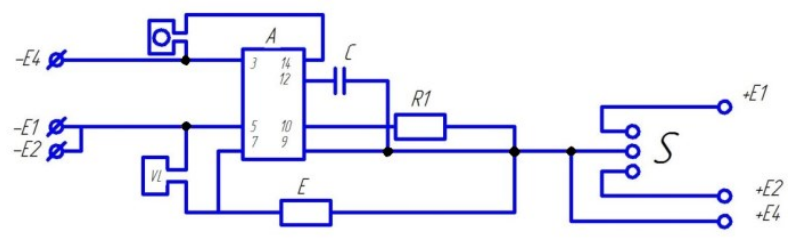

Fig. 4. Scheme for control the microcircuit operation.

Test for faultless is carried out by method 700-1 OST $11073.013-83$ at the temperature $+850 \mathrm{C}$. The scheme of switching on in case of tests is provided on fig. 5 .

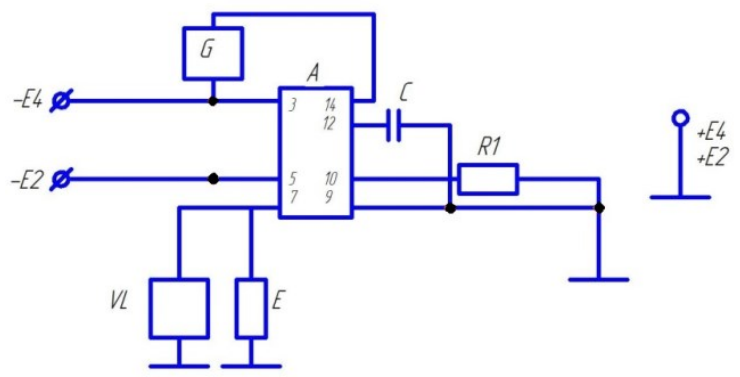

Fig. 5. Scheme of microcircuits testing for faultless and durability.

The holding time in normal conditions before measurement the parameters $-2 \mathrm{~h}$.

Some questions of increasing the efficiency of ERP control are given in [19-24].

\section{Conclusion}

The made analysis revealed a row of problems when carrying out a learning experiment with bipolar microcircuits: absence of the approved schemes of switching on when carrying out investigation tests and low informtiveness of parameters by development the expected models. For 522 series microcircuits as the informative parameter it is recommended to use the value of residual voltage. Schemes of measurement of residual voltage, actuation voltages, consuming current, operating control, test for faultless are offered.

\section{References}

[1] Piganov MN. Technological bases of support the microassemblies quality. Samara: SGAU, 1999; $231 \mathrm{p}$.

[2] Piganov MN. Individual prediction the quality indices of elements and components of microassemblies. M.: New technologies, $2002 ; 267$ p.

[3] Zhadnov VV. Prediction of reliability the electronic means with mechanical elements. Ekaterinburg: LLC Fort Dialog, 2014 ; 172 p.

[4] Keydzhyan GA. Prediction the reliability of microelectronic equipment on the basis of the large-scale integrated circuit. M.: Radio and communication, $1987 ; 152 \mathrm{p}$.

[5] Tyulevin SV, Piganov MN, Erantseva ES. To the problem of prediction the quality indices space equipment elements. Reliability and quality of multiple systems 2014; 1(5): 9-17.

[6] Tyulevin SV, Piganov MN. Methods of learning experiment in the case of individual prediction the quality indices of space RES. Actual problems of radioelectronics and telecommunications: mater. of all-russian STC. Samara: SGAU, 2008; 239-253.

[7] Berenstein GV, Dyachenko AM. Prediction of IC quality on the basis of internal voltages analysis. Physical bases of reliability and degradation of semiconductor devices: thesises of repost at All-Union conf. Chisinau 1991; II: 36.

[8] Sergeyev VA. Characteristics and features of selective distributions of powerful bipolar transistors on thermophysical parameters. News of the Samara scientific center of RAS 2004; 1: 154-160.

[9] Gorlov MI, Zharkikh AP. Device for control the charge stability of semiconductor products using corona discharge. Russian Federation Patent 2312424. Publ. 10.12.2007. Bulletin No. 34.

[10] Luchino AI, Savin AS. Researches the possibility of individual prediction the durability of transistors by image identification. Electronic engineering 1976; 8(10): 3-9.

[11] Aladinskiy VK, Gavrilov VYu, Gorelkina EN. The critical supply voltage as the informative parameter in case of CMOS IC electrophysical diagnosing. Electronic engineering 1990; 2(4): 87-90.

[12] Sergeyev VA, Yudin VV. Quality control of digital integrated microcircuits by parameters of the thermal communications matrix. News of higher education institutions. Electronics 2009; 6: 72-78.

[13] Chang MH, Das D, Varde PV, Pecht M. Light emitting diodes reliability review. Microelectronics Reliability 2012; 5: 762-782.

[14] Kuba J. Applicaion of low temperature infailure diagnostics of semiconductor devices. Power Semic. Hybrid Device - 8-th Int. Spring Semin. Electrotechnol. Prenet 1985; 31-34.

[15] Kleshko VM, Semenov AS. Quality control and reliability of semiconductor devices using m-characteristics. Electronic equipment 1974; 8(12): 17-21.

[16] Watchik R, Bucelot T, Li G. J. Appl. Phys. 1998; 9: 4734-4740. 
[17] Gorlov MI, Vinokurov AA. The influence of electrostatic discharges on the critical power supply voltage of K561LNZ type. Solid state electronics, microelectronics and nanoelectronics: collection of scientific papers. Voronezh, 2011; 10: 96-98.

[18] Piganov MN. Metrological aspects of microassemblies quality assurance. Modern information and electronic technologies: Proceedings of the 3rd international scientific practical conference. Ukraine, Odessa, 2002: 140.

[19] Mishanov R, Piganov M. Individual forecasting of quality characteristics by an extrapolation method for the stabilitrons and the integrated circuits. The Experience of Designing and Application of CAD Systems in Microelectronics: proceeding XIII international conference. Ukraine, Lviv, 2015: 242244.

[20] Piganov M, Tyulevin S, Erantseva E. Individual prognosis of quality indicators of space equipment elements. The Experience of Designing and Application of CAD Systems in Microelectronics: proceeding XIII international conference. Ukraine, Lviv, 2015 : 367-371.

[21] Piganov MN, Tyulevin SV, Erantseva ES, Mishanov RO. Apparatus diagnostic for non-destructive control chip CMOS-type. European Science and Technology: materials of the VII international research and practice conference. Germany, Munich, 2014: 398-401

[22] Jonson JB. The Sholiky effect in low frequency circuits. Phys. Rev. 1925; 26: 71-85.

[23] Mishanov RO. The installation of diagnostic non-destructive control for the bipolar IC. Science and Education: materials of the VII international research and practice conference. Germany, Munich, 2014: 227-232.

[24] Mishanov RO, Piganov MN. Technology of diagnostic for non-destructive control of the bipolar integrated circuits. Sense. Enable. Spitse: proceedings 2-nd international scientific symposium. Russia, St. Petersburg, 2015: 38-41. 